\title{
Антропоморфная статуэтка из кургана эпохи бронзы некрополя у поселка Заозерное в Северо-Западном Крыму
}

\begin{abstract}
Аннотаиия. В некрополе у поселка Заозерное на окраине г. Евпатории в Северо-Западном Крыму, в кургане эпохи бронзы была найдена антропоморфнал статуэтка. Курган был ограблен еще в древности, поэтому статуэтка находилась не в погребении, а на материке - между двумя погребениями эпохи бронзы. Она представляет собой весъма схематичное изображение женской фигурь. Антропоморфная пластика характерна для многих культур эпохи бронзы, в том числе для трипольской культуры. Набор подобных статуэток находился в погребении 26 кургана 6 у села Зеленый Гай на реке Ингулеи. Зеленогайский комплекс датируется временем позднего Триполья, и тип статуэток имеет много общего с трипольской антропоморфной пластикой. Заозерненская статуэтка практически аналогична статуэткам Зеленогайского комплекса, поэтому ее можно считать относяшейся к трипольской культуре, ее финальному этапу. Находка статуэтки в кургане некрополя у поселка Заозерный говорит, по-видимому, о связи степного Крьма с культурами круга Триполья.
\end{abstract}

Ключевые слова: эпоха бронзы, антропоморфная пластика, трипольская культура, женская статуэтка, степной Крым, некрополь Заозерное, Зеленогайский комплекс, погребальный обряд, «серезлиевский» тип, ингульская группа.

Abstract. An anthropomorphic figurine has been found in a mound from the Bronze Age located in the necropolis by the village of Zaozernoe on the periphery of the town of Yeupatoria in North-Western Crimea. The mound had been robbed in Antiquity which is why the figurine was found not in the burial itself, but in the strata between two Bronze Age burials. The figurine is a rather schematic representation of a female figure. Anthropomorphic sculptures are typical of many Bronze Age cultures, including the Trypillian culture. A collection of similar figurines was found in mound 6 of the burial site 26 in the village of Zelenyi Hai on the river Inhulets. The Zelenohai complex is dated to the period of late Trypillia and the figurines' type has a lot in common with Trypillian anthropomorphic sculpture. The Zaozernoe figurine is almost completely identical to the figurines in the Zelenohai complex and consequently can be ascribed to the Trypillian culture - to its final phase. The discovery of the figurine in the mound of the necropolis by the village of Zaozernoe attests, it seems, to the links between the Crimean steppe and the cultures from the circle of Trypillia.

Key words: Bronze Age, anthropomorphic sculpture, Trypillian culture, female figurine, Crimean steppe, Zaozernoe necropolis, Zelenohai complex, burial rite, "serezlievskiy" type, Inhul group.

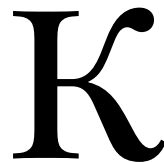

урганный некрополь у пос. Заозерное на окраине Евпатории возник в античную эпоху на месте могильника бронзового века. Античные погребения впускались в курганы эпохи бронзы, что нарушало ранние захоронения. Кроме того, некрополь неоднократно подвергался ограблениям, также способствовавшим разрушению объектов. Поэтому погребения бронзового века зачастую определяются либо по стратиграфическому расположению, либо по находкам инвентаря, либо по позе погребенного - по так называемому скорченному положению костяка.

В кургане №17 были открыты остатки, по крайней мере, трех погребений эпохи бронзы.
Насыпь кургана испорчена четырьмя грабительскими ямами, поэтому сохранность погребений очень плоха.

Погребение №1 находилось под каменным закладом и непосредственно под каменной, хорошо обработанной антропоморфной плитой без изображений, обычной для погребений бронзового века. Тип такого надгробия с небольшим выступом, изображавшим голову, относится, вероятнее всего, к ЯКИО. Наша стела учтена Г.Н. Тощевым и отнесена им к первой группе надгробий ЯКИО по условиям находки как являющаяся элементом перекрытия [1, с. 89, рис. 40, 4]. Распространение ямной культуры в Крыму датируется 2600/2500-2200 гг. до н. ә. 


\section{Исторический журнал: научные исследования № 6 (36) • 2016}

DOI: 10.7256/2222-1972.2016.6.19202

[1, с. 208]. Следовательно, погребение №1 кургана 17 датируется, вероятно, этим временем. От скелета осталось лишь несколько костей, поэтому определить положение костяка оказалось невозможным. В заполнении могилы находились фрагменты лепного сосуда, сколы кремня и обломки раковины. Недалеко от погребения, на той же глубине, лежали фрагменты лепного неорнаментированного круглодонного сосуда. Подобные сосуды, так называемые кубки, характерны для керамических комплексов бронзовой эпохи Крыма, особенно ее финального этапа [2, рис. 22,$2 ; 5$, рис. $23,1,2,6 ; 3$, рис. $61,4,5,7]$. В основном распространение они получают в белозерской культуре, территорию которой Г. Н. Тощев определяет, вслед за В. В. Отрощенко, как степной Крым включительно до горной части [1, с. 195]. Датируется время распространения этой культуры XII-Х вв. до н. э. [4, с. 171-172].

Погребение №3 определяется как относящееся к бронзовому веку по позе погребенного так называемой скорченной.

В погребении №4 лежали останки двух погребенных. Несмотря на плохую сохранность костей, представилось возможным заключить, что они принадлежали взрослому и ребенку. По положению костей взрослого можно предположить, что его поза была скорченной.

Два погребения, относящихся к эпохе бронзы лишь по позе скелетов - так называемой скорченной - могут датироваться, начиная от позднекатакомбного времени до времени распространения белозерской культуры. Памятники ККИО Крыма Г. Н. Тощев датирует XXIIXVIII вв. до н. э. [1, с. 209]. Время же распространения белозерской культуры в Крыму датируется XII-Х вв. до н. э. [4, с. 171-172].

Столь разновременные - от ямного до белозерского времени - погребения в одном кургане - обычная ситуация в эпоху бронзы. Примером может служить курган у с. Песчаное близ Евпатории в Северо-Западном Крыму [5, с. 4-8].

На участке между погребениями №3 и №4, на материке были найдены кремневые отщепы и миниатюрная антропоморфная глиняная статуэтка, выполненная из светлой глины с черными включениями (рис.1). Вероятнее всего, она принадлежала одному из этих погребений. В настоящее время статуэтка находится в экспозиции Евпаторийского краеведческого музея. Размеры ее: высота - 5,2 см, ширина с одной стороны - 2,2 см, ширина с другой стороны - 1,0 см.
Находка такой статуэтки не просто редкость в Крыму - она единственная, по крайней мере, в опубликованных материалах подобные предметы не встречаются. Впервые изображение заозерненской статуэтки было опубликовано сразу после находки, но ее датировка и культурная принадлежность не атрибутировались [6, с. 283-284]. Поскольку она была найдена вне погребения, датировать ее можно приблизительно по соседним погребениям, что представляет значительную трудность в связи с их весьма плохой сохранностью.

Поиск культурной принадлежности статуэтки оказался осложненным тем, что первоначально было неправильно понято положение статуэтки в пространстве: верхом считалась расширяющаяся раструбом часть, а нижней - конусная. Таким образом она располагалась в первой публикации [6, с. 284] и в монографии В. А. Дергачева и И. В. Манзуры, поместивших статуэтку из Заозерного в группу Усатовских памятников [7, рис. 86]. Установить правильное ее расположение и, соответственно, адекватно интерпретировать помогла сводка подобных вещей И. Ф. Ковалевой, которая определила заозерненскую статуэтку как аналогию Зеленогайского комплекса антропоморфной пластики в случае ее правильного расположения [8, с. 116].

Статуэтка представляет собой очень схематичную, но при этом с явными чертами антропоморфности фигурку в виде столбика, в нижней части расширяющегося, в верхней- сужающегося, в форме конуса (рис. 1). Антропоморфность выражена изображением женской груди, показанной двумя выступами науровне «рук». «Руки»два коротких отростка округлой формы, слегка отведенные назад. Передняя часть статуэтки заглажена и имеет небольшую вогнутость. Оборотная сторона фигурки, ее верхняя часть, орнаментирована. Орнамент представляет собой прочерченные линии, образующие углы, направленные вершинами вниз, между линиями помещены короткие вертикальные черточки; внизу, по бокам, расположены концентрические полуокружности. В нижней части орнаментальное поле завершается рядом вертикальных черточек, аналогичных изображенным между линиями, но не замкнутых. Орнамент слегка заходит на боковые стороны. Оборотная сторона немного выпукла. Нижняя часть с обратной стороны статуэтки представляет собой вогнутую уплощенную поверхность, по бокам расширяющуюся, с закругленным краем. Технологически 


\section{Исторические источники и артефакты}

фигурка выполнена из цельного куска глины, вернее сказать - вылеплена.

Таким образом, статуэтка представляет собой максимально обобщенное, схематичное изображение женской фигуры. Самые близкие аналогии нашей статуэтке - из Зеленогайского комплекса и из с. Новоалександровка (рис. 2).

Исследователи по-разному интерпретировали отдельные части фигур. Т.С. Пассек считала, что это стоящие женские фигуры, «у которых плечи обозначены обычными для трипольских схематических статуэток выступами, переходящими в уширенное плоское основание», a «цилиндрообразные» верхние части фигур это «головы на вытянутой, округлой в сечении шее» [9, с. 199-202]. В.Д. Рыбалова предлагает «принять выступы за обозначение бедер, а цилиндрообразные и конусообразные верхние части скульптур рассматривать как слитные изображения женских голов и торсов» [10, с. 84]. И. Ф. Ковалева выступы принимала за «седалище», а нижнюю расширяющуюся часть называла постаментом [8, 107-109]. Находка нашей статуэтки позволяет снять эти разногласия: изображение женской груди на уровне выступов убеждает в том, что это, как считала Т. С. Пассек, руки. В свое время С. Н. Бибиков утверждал, что боковые выступы - локти сложенных на груди или под грудью рук, приводя в качестве аналогий более реалистические статуэтки с изображением такого их расположения [11, с. 228]. Относительно интерпретации нижней части нашей статуэтки можно с достаточной долей уверенности говорить, что это бедра.

Верхняя конусообразная часть заозерненской статуэтки схематически изображает голову на длинной шее, что традиционно для трипольских статуэток [12, с. 19, 98, 106, рис. 2, 32]. Орнаментация оборотной стороны фигурки может быть интерпретирована как прическа, аналогичная занесенной А. П. Погожевой в таблицу «Виды причесок», встреченной на статуэтке из Владимировки [12, с. 124, табл. 17].

Еще одна особенностьстатуэтокэтого типавогнутость передней части. На нашей фигурке этот признак выражен очень слабо, тем не менее он присутствует. Возможно, автор был далек от понимания истоков традиции таких изображений, и основой для создания статуэтки служила знаковая память. О том, что подобные изображения - максимально обобщенные, даже схематичные - становятся знаком, свидетельствует линия развития мелкой пластики Трипо-
DOI: $10.7256 / 2222-1972.2016 .6 .19202$
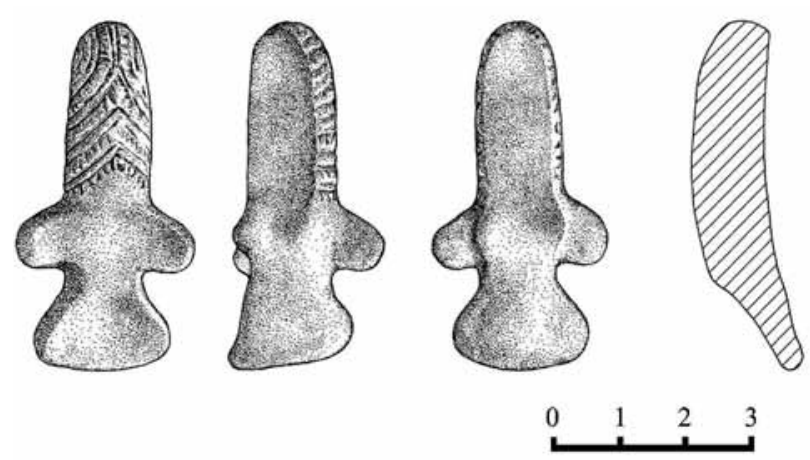

Рис. 1. Статуэтка из кургана 17 некрополя у с. Заозерное
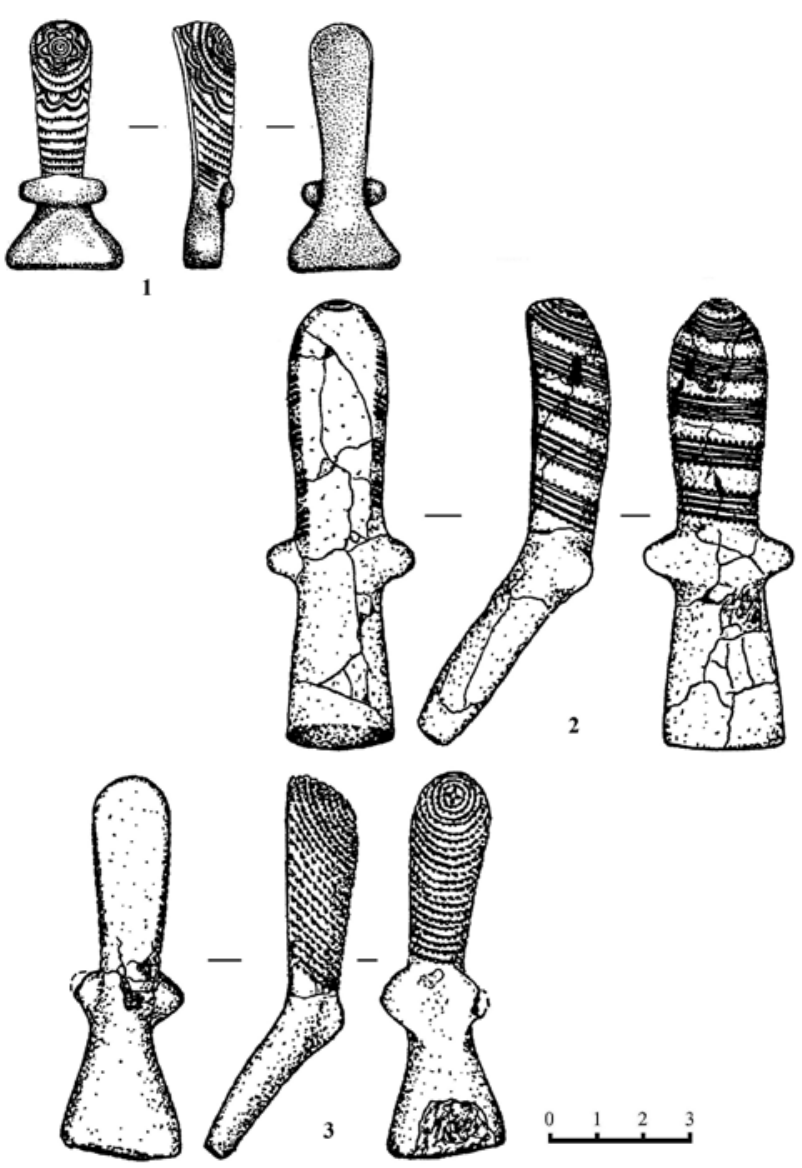

Рис. 2.1 - с. Новоалександровка;

2, 3 - Зеленогайский комплекс (по И.Ф. Ковалевой)

лья. Причем предельно схематичные статуэтки характерны именно для степной части Триполья, что отмечала Т. Г. Мовша [13, с. 28]. Позднее исследовательница связывала статуэтки «серезлиевского» типа с касперовской культурной группой позднего Триполья Буго-Днепровского междуречья [14, с. 118]. 


\section{Исторический журнал: научные исследования № 6 (36) • 2016}

DOI: $10.7256 / 2222-1972.2016 .6 .19202$

Прообразом статуэток с вогнутой передней частью были распространенные в ранней трипольской культуре изображения сидящих женщин [12, с. 32, рис. 7, 5]. Возможно, этим объясняется впадина на оборотной стороне нижней части статуэтки из нашего некрополя, предназначавшаяся для крепления ее на какой-то плоскости. Однако есть и другая интерпретация наклона вперед верхней части статуэтки. Так, Н. Б. Бурдо предполагает, что таким образом изображалась поза молящейся женщины [15, c. 174]. Интересно предположение М. Т. Гембарович о связи сидячих женских статуэток с культово-магическим обрядом, главным элементом которого была женская фигура на качелях, воплощавшая хтоническое божество, традицию, корни которого исследовательница находит в эгейском мире [16, с. 108-111].

Один из основных вопросов, касающихся антропоморфной пластики, - назначение трипольских статуэток. Все исследователи не сомневаются в их сакрально-культовом значении [11, с. $260 ; 16$, с. $106-123 ; 17$, с. 96-100]. Интерпретация назначения статуэток связана прежде всего с местами находок подобных предметов. На территориях ареала трипольской культуры женские статуэтки присутствовали как в домах и святилищах [12, с. 111-115; 13, с. 201-205], так и в погребениях [7]. Находки на поселениях позволили А.П. Погожевой установить их полифункциональность как охранительниц дома, очага, посредниц между людьми и божествами $[12$, c. 115$]$.

В целом же исследовательница считает, что «каждый тип и подтип статуэток представляет определенный антропоморфный образ, воплощающий определенную идею в рамках широко понимаемого культа плодородия» [12, с. 132]. В таком же ключе - как женского божества, хранительницы дома - видит семантику статуэток В. Г. Петренко [17, с. 99].

Помещение статуэток в погребения предполагает, возможно, несколько иную сакральную окраску. Поскольку статуэтка из Заозерного происходит именно из погребения, на функциях подобных предметов надо остановиться более подробно. Антропоморфная пластика и, в частности, женские изображения, были распространены во многих культурах эпохи бронзы Евразии. Е.В. Антонова относительно помещения статуэток в могилы земледельцев Передней и Средней Азии предположила, что это были изображения индивидуальных покровителей погребенных
[18, с. 116]. К более глобальной идее склоняется А.П. Погожева, считавшая ритуал помещения статуэток в погребения отражением переплетения в сознании трипольцев представлений о жизни и смерти, о непрерывности цикла рождение-жизнь-смерть-возрождение [12, с. 115]. Особенно это касается детских погребений. В этом смысле интересно вспомнить, что заозерненская статуэтка найдена недалеко от погребения взрослого и ребенка. Также в детском погребении находилась фигурка типа Зеленогайского комплекса в кургане у с. Баратовка [19, с. 252]. В.Г. Збенович обращает внимание на преимущественное присутствие статуэток «серезлиевского» типа в детских погребениях и видит в этом связь с трипольскими культовыми воззрениями [20, с. 66]. Э.Ф. Патокова видела в антропоморфных изображениях семейных идолов-оберегов [21, с. 17]. Возможно, это подтверждается совпадением в Зеленогайском погребении количества похороненных с количеством статуэток [22, с. 73 , рис. 26]. И.Ф. Ковалева считает, что сосредоточение антропоморфных статуэток в погребениях детей и подростков связано с обрядами жизненного цикла и статуэтки изображали духов-покровителей, призванных обеспечивать благополучие и продолжение семьи и рода $[8$, c. 124]. Некоторые исследователи связывали статуэтки с земледельческой обрядностью плодородия, т. к. иногда они были намеренно разбиты [23, с. 105].

Каким образом статуэтки использовались в ритуале? Миниатюрность статуэток - 5-9 см в высоту - предполагает частный характер их использования. Их удобно держать на ладони, тем более что «спинка» выпукла, т. е. статуэтка, возможно, участвовала в погребальном обряде перед ее окончательным помещением в могилу [24, c. 81]. Неясным остается вопрос: изготавливались ли статуэтки специально для погребений или служили своим хозяевам при жизни? Статуэтки типа Зеленогайского комплекса найдены только в погребениях, что позволяет предполагать их погребальную принадлежность. Но пока приходится согласиться с И. Ф. Ковалевой, что более адекватная интерпретация значения антропоморфных статуэток требует дальнейших усилий в изучении знаковых систем культур степного энеолита [8, с. 124].

Датировку нашей статуэтки можно определять в контексте хронологии погребений кургана, на территории которого она была найдена, и этот вопрос связан с определением археологи- 


\section{Исторические источники и артефакты}

ческой культуры, к которой надо отнести погребения кургана 17. Однако, как мы уже говорили, значительные расхождения в хронологии и, соответственно, в культурной их принадлежности внутри кургана не позволяют датировать статуэтку. В связи с этим особую важность приобретает определение ее культурной принадлежности и, соответственно, времени изготовления и использования.

Культурная принадлежность нашей статуэтки - вопрос сложный. Он окончательно не решен и для аналогичных заозерненской статуэтке памятников. Мнения исследователей различны. В.А. Дергачев и И.В. Манзура считают памятники Северо-Западного Причерноморья локальными вариантами позднетрипольской культуры [7, с. 11]. Принадлежность трипольской культуре статуэток, подобных заозерненской, утверждает А.П. Погожева [12]. По мере накопления материалов менялись и взгляды на культурную принадлежность женских статуэток типа «серезлиевских», названных по месту первой находки [25, с. 7-19]. Но в большинстве работ статуэтки этого типа из районов, не относящихся непосредственно к ареалу трипольской культуры, рассматриваются как трипольские импорты в культуры степного энеолита [26, с 17-30; 27, с. 9; 20, с. 63]. Л. П. Крылова, исследовавшая погребальные памятники на р. Ингулец, где в одном из курганов находилась статуэтка типа Зеленогайского комплекса, предложила называть подобные памятники бассейна Южного Буга - Ингула - Ингульца «ингульской культурной группой» [28, с. 18-20]. Позднее В.А. Трифонов датировал ингульскую группу этапом средней бронзы - 2500-2300 гг. до н. э. [29, с. 95-160].

И.Ф. Ковалева рассматривает комплексы с антропоморфной пластикой «серезлиевского» типа как принадлежащие населению постмариупольской культуры, оказавшемуся в ИнгулецкоИнгульском междуречье в результате перемещения племенных образований трипольской общности [30, с. 61-70].

Практически полные аналогии статуэтки из некрополя у Заозерного с комплексом антропоморфной пластики Зеленогайского кургана 6 позволяют отнести ее к культурам, так или иначе связанным с культурой Триполья - ингульской и постмариупольской [3, с. 120].

Таким образом, находка статуэтки в некрополе у пос. Заозерное позволяет предположить, что степной Крым в эпоху бронзы каким-то образом был связан с культурами Поднепровья, относящимися к вариантам трипольской культуре.

\section{Библиография:}

1. Тощев Г. Н. Крым в эпоху бронзы. Запорожье: ЗНУ, 2007. 303 с.

2. Колотухин В. А. Горный Крым в эпоху поздней бронзы - начале железного века. Киев: Южногородские ведомости, 1996. $160 \mathrm{c.}$

3. Колотухин В. А. Поздний бронзовый век Крыма. Киев: Стилос, 2003. 138 с.

4. Отрощенко В. В. Проблеми периодізації культур середньої та пізньої бронзи Пивдня Східної Європи (культурностратиграфічні зіставлення). Київ: Видавництво КИУ, 2001. 290 с.

5. Барбарунова 3. А. Курган у села Песчаное близ города Евпатории // Памятники бронзового и железного веков в окрестностях Евпатории. М.: Издательство Московского университета, 1993. С. 3-11.

6. Калмыкова В. А., Коновалов А. А., Павлов В. А. Курганный могильник у деревни Заозерное // Археологические открытия за 1975 год. М.: Наука, 1976. С. 283-284.

7. Дергачев В. А., Манзура И. В. Погребальные комплексы позднего Триполья. Кишинев: Штиинца, 1991.337 с.

8. Ковалева И. Ф. Зеленогайский комплекс антропоморфной пластики: культурная принадлежность и семантика // Курганы энеолита-бронзы в Криворожском течении Ингульца. Дніпропетровськ: Видавництво Дніпропетровського університету, 2003. С.102-130.

9. Пассек Т. С. Периодизация трипольских поселений / Материалы и исследования по археологии СССР. Вып. 10. М.: Издательство АН СССР, 1949. 247 с.

10. Рыбалова В. Д. Некоторые новые данные к изучению позднетрипольской культуры на Южном Буге // Археологический сборник Государственного Эрмитажа.Вып. 6. Л.: Издательство АН СССР, 1964. С. 79-85.

11. Бибиков С. Н. Поселение Лука-Врублевецкая // Материалы и исследования по археологии СССР. Вып. 38. М.: Издательство АН СССР, 1953. 460 с.

12. Погожева А. П. Антропоморфная пластика Триполья. Новосибирск: Наука, 1983. 144 с.

13. Мовша Т. Г. Святилища трипольской культуры // Советская археология. 1971. №1. С. 201-205.

14. Мовша Т. Г. Хронология Триполья-Кукутени и степные культуры эпохи раннего металла в ее системе // Проблемы археологии Поднепровья. Днепропетровск: Б. и., 1984. С. 60-83.

15. Бурдо Н. Б. Сакральний світ трипільскої цивілізації. Київ: Електронне видання, 2005. 305 с.

16. Гембарович М. Т. К вопросу о значении трипольских женских статуэток // Советская археология. 1956. Т. ХХ. С. 106-123.

17. Петренко В. Г. О семантике усатовской антропоморфной пластики // Северо-Западное Причерноморье в эпоху первобытнообщинного строя. Киев: Наукова думка, 1980. С. 96-100. 


\section{Исторический журнал: научные исследования № 6 (36) • 2016}

DOI: $10.7256 / 2222-1972.2016 .6 .19202$

18. Антонова Е. В. Антропоморфная скульптура древних земледельцев Передней и Средней Азии. М.: Наука, 1977.225 с.

19. Елагина Н. Г., Петренко В. Г. Раскопки курганов на Ингульце // Археологические открытия за 1968 г. М.: Наука, 1969. С. 252-253.

20. Збенович В. Г. К проблеме связей Триполья с энеолитическими культурами Северного Причерноморья // Энеолит бронзовый век Украины. Киев: Наукова думка, 1976. С. 57-69.

21. Патокова Э. Ф. Антропоморфная пластика Маяцкого могильника // Памятники древнего искусства Северо-Западного Причерноморья. Киев: Наукова думка, 1986. С. 5-20.

22. Ковалева И. Ф., Марина З. П., Ромашко В.А. и др. Курганы энеолита-бронзы в Криворожском течении Ингульца. Дніпропетровськ: Видавництво Дніпропетровського університету, 2003. 131 с.

23. Патокова Э. Ф., Петренко В. Г., Бурдо Н. Б., Полищук Л. Ю. Памятники трипольской культуры в Северо-Западном Причерноморье. Киев: Наукова думка, 1989. 144 с.

24. Усачук А. Н., Полидович Ю.Б. Антропоморфная фигурка эпохи бронзы из Донецкой области // Археологический альманах. 2010. № 21. С. 78-85.

25. Щербаковский Д. М. Раскопки курганов на пограничье Херсонской и Киевской губерний // Археологическая летопись Южной России. 1905. № 1-2. С. 7-19.

26. Телегін Д. Я. Про культурну належність і датування випростаних енеолітичних поховань Степового Подніпров'я // Археологія. 1987. Вип. 60. С. 17-30.

27. Шапошникова О. Г., Бочкарев В. С., Шарафутдинова И. Н. О памятниках эпохи меди - ранней бронзы в бассейне р. Ингула // Древности Поингулья. Киев: Наукова думка, 1977. 148 с.

28. Крилова Л. П. Археологічні розкопки стародавніх курганів на Криворіжжі в 1964-1966 рр. // Наш край. Дніпропетровськ: Промінь, 1971. С. 18-31.

29. Трифонов В. А. Степное Прикубанье в эпоху энеолита - средней бронзы (периодизация) // Древние культуры Прикубанья. Л.: Наука, 1991. С. 92-166.

30. Ковалева И. Ф. «Вытянутые» погребения Днепровского ареала Волго-Днепровской культурно-исторической общности эпохи энеолита // Курганные древности степного Поднепровья (III-I тыс.до н.э.). Вып. 3. Днепропетровск: Издательство Днепропетровского университета, 1979. С. 61-70.

\section{References (transliterated):}

1. Toshchev G. N. Krym v epokhu bronzy. Zaporozh'e: ZNU, 2007. 303 s.

2. Kolotukhin V. A. Gornyi Krym v epokhu pozdnei bronzy - nachale zheleznogo veka. Kiev: Yuzhnogorodskie vedomosti, 1996.160 s.

3. Kolotukhin V. A. Pozdnii bronzovyi vek Kryma. Kiev: Stilos, 2003.138 s.

4. Otroshchenko V. V. Problemi periodizatsiï kul'tur seredn'oïi ta pizn'oï bronzi Pivdnya Skhidnoï Evropi (kul'turno-stratigrafichni zistavlennya). Kiïv: Vidavnitstvo KIU, 2001. 290 s.

5. Barbarunova Z. A. Kurgan u sela Peschanoe bliz goroda Evpatorii // Pamyatniki bronzovogo i zheleznogo vekov v okrestnostyakh Evpatorii. M.: Izdatel'stvo Moskovskogo universiteta, 1993. S. 3-11.

6. Kalmykova V. A., Konovalov A. A., Pavlov V. A. Kurgannyi mogil'nik u derevni Zaozernoe // Arkheologicheskie otkrytiya za 1975 god. M.: Nauka, 1976. S. 283-284.

7. Dergachev V. A., Manzura I. V. Pogrebal'nye kompleksy pozdnego Tripol'ya. Kishinev: Shtiintsa, 1991.337 s.

8. Kovaleva I. F. Zelenogaiskii kompleks antropomorfnoi plastiki: kul'turnaya prinadlezhnost' i semantika // Kurgany eneolitabronzy v Krivorozhskom techenii Ingul'tsa. Dnipropetrovs'k: Vidavnitstvo Dnipropetrovs'kogo universitetu, 2003. S.102-130.

9. Passek T. S. Periodizatsiya tripol'skikh poselenii / Materialy i issledovaniya po arkheologii SSSR. Vyp. 10. M.: Izdatel'stvo AN SSSR, 1949. 247 s.

10. Rybalova V. D. Nekotorye novye dannye k izucheniyu pozdnetripol'skoi kul'tury na Yuzhnom Buge // Arkheologicheskii sbornik Gosudarstvennogo Ermitazha.Vyp. 6. L.: Izdatel'stvo AN SSSR, 1964. S. 79-85.

11. Bibikov S. N. Poselenie Luka-Vrublevetskaya // Materialy i issledovaniya po arkheologii SSSR. Vyp. 38. M.: Izdatel'stvo AN SSSR, 1953. $460 \mathrm{~s}$.

12. Pogozheva A. P. Antropomorfnaya plastika Tripol'ya. Novosibirsk: Nauka, 1983. 144 s.

13. Movsha T. G. Svyatilishcha tripol'skoi kul'tury // Sovetskaya arkheologiya. 1971. №1. S. 201-205.

14. Movsha T. G. Khronologiya Tripol'ya-Kukuteni i stepnye kul'tury epokhi rannego metalla v ee sisteme // Problemy arkheologii Podneprov'ya. Dnepropetrovsk: B. i., 1984. S. 60-83.

15. Burdo N. B. Sakral'nii svit tripil'skoï tsivilizatsiï. Kiïv: Elektronne vidannya, 2005. 305 s.

16. Gembarovich M. T. K voprosu o znachenii tripol'skikh zhenskikh statuetok // Sovetskaya arkheologiya. 1956. T. XX. S. $106-123$.

17. Petrenko V. G. O semantike usatovskoi antropomorfnoi plastiki // Severo-Zapadnoe Prichernomor'e v epokhu pervobytnoobshchinnogo stroya. Kiev: Naukova dumka, 1980. S. 96-100.

18. Antonova E. V. Antropomorfnaya skul'ptura drevnikh zemledel'tsev Perednei i Srednei Azii. M.: Nauka, 1977.225 s.

19. Elagina N. G., Petrenko V. G. Raskopki kurganov na Ingul'tse // Arkheologicheskie otkrytiya za 1968 g. M.: Nauka, 1969. S. 252253.

20. Zbenovich V. G. K probleme svyazei Tripol'ya s eneoliticheskimi kul'turami Severnogo Prichernomor'ya // Eneolit - bronzovyi vek Ukrainy. Kiev: Naukova dumka, 1976. S. 57-69.

21. Patokova E. F. Antropomorfnaya plastika Mayatskogo mogil'nika // Pamyatniki drevnego iskusstva Severo-Zapadnogo Prichernomor'ya. Kiev: Naukova dumka, 1986. S. 5-20.

22. Kovaleva I. F., Marina Z. P., Romashko V.A. i dr. Kurgany eneolita-bronzy v Krivorozhskom techenii Ingul'tsa. Dnipropetrovs'k: Vidavnitstvo Dnipropetrovs'kogo universitetu, 2003. $131 \mathrm{s.}$ 


\section{Исторические источники и артефакты}

DOI: $10.7256 / 2222-1972.2016 .6 .19202$

23. Patokova E. F., Petrenko V. G., Burdo N. B., Polishchuk L. Yu. Pamyatniki tripol'skoi kul'tury v Severo-Zapadnom Prichernomor'e. Kiev: Naukova dumka, 1989. $144 \mathrm{~s}$.

24. Usachuk A. N., Polidovich Yu.B. Antropomorfnaya figurka epokhi bronzy iz Donetskoi oblasti // Arkheologicheskii al'manakh. 2010. № 21. S. 78-85.

25. Shcherbakovskii D. M. Raskopki kurganov na pogranich'e Khersonskoi i Kievskoi gubernii // Arkheologicheskaya letopis' Yuzhnoi Rossii. 1905. № 1-2. S. 7-19.

26. Telegin D. Ya. Pro kul'turnu nalezhnist' i datuvannya viprostanikh eneolitichnikh pokhovan' Stepovogo Podniprov'ya // Arkheologiya. 1987. Vip. 60. S. 17-30.

27. Shaposhnikova O. G., Bochkarev V. S., Sharafutdinova I. N. O pamyatnikakh epokhi medi - rannei bronzy v basseine r. Ingula // Drevnosti Poingul'ya. Kiev: Naukova dumka, 1977.148 s.

28. Krilova L. P. Arkheologichni rozkopki starodavnikh kurganiv na Krivorizhzhi v 1964-1966 rr. // Nash krai. Dnipropetrovs'k: Promin', 1971. C. 18-31.

29. Trifonov V. A. Stepnoe Prikuban'e v epokhu eneolita - srednei bronzy (periodizatsiya) // Drevnie kul'tury Prikuban'ya. L.: Nauka, 1991. S. 92-166.

30. Kovaleva I. F. «Vytyanutye» pogrebeniya Dneprovskogo areala Volgo-Dneprovskoi kul'turno-istoricheskoi obshchnosti epokhi eneolita // Kurgannye drevnosti stepnogo Podneprov'ya (III-I tys.do n.e.). Vyp. 3. Dnepropetrovsk: Izdatel'stvo Dnepropetrovskogo universiteta, 1979. S. 61-70. 